\title{
FINGERPRINT VERIFICATION BY USING MINUTIAE MATCHING TECHNIQUE
}

Bappa Sarkar ${ }^{\# 1}$,Joyassree Sen ${ }^{\# 2}$,Md. Atiqur Rahman ${ }^{\# 3}$ and Md. Habibur Rahman"4 \#1 Assistant Professor, Computer Science \& Engineering Department, Islamic University, Kushtia, bappa@cse.iu.ac.bd

\#2 Assistant Professor, Computer Science \& Engineering Department, Islamic University, Kushtia, joyassree@cse.iu.ac.bd

\#3 Assistant Professor, Computer Science \& Engineering Department, Islamic University, Kushtia, atique0528@gmail.com

\#4 Assistant Professor, Computer Science \& Engineering Department, Islamic University, Kushtia, habibiucse@gmail.com

Fingerprint verification is one of the most reliable personal identification methods. Most automatic systems for fingerprint comparison are based on minutiae matching. Minutiae are essentially terminations and bifurcations of the ridge lines that constitute a fingerprint pattern. Automatic minutiae detection is an extremely critical process, especially in low-quality fingerprints where noise and contrast deficiency can originate pixel configurations similar to detect false minutiae or hide real minutiae [14]. Several approaches have been proposed to find minutiae. This report concerns the design and implementation of a fingerprint verification system using a new algorithm. The purpose of the study was to implement the fingerprint Verification System. Main issues encountered are image enhancement, feature extraction, template generation and verification. In this work a new approach is proposed, based on ridge-line following, where the minutiae are extracted directly from grayscale images [14]. Finally, a number of simulations were performed and evaluated. In spite of a greater conceptual complexity, the proposed method performs better both in terms of efficiency and robustness. Overall results were considered sufficiently well, and met the predefined specifications.

Keywords:Fingerprint recognition, Minutiae matching technique, Pattern recognition, Biometric recognition

\section{Introduction}

Over the last 10 - 15 years organizations and corporations have increasingly been distributing access to information throughout their organization. When having made information so available, it is necessary to secure access to the information to authorized personnel only. A person's claimed identity has to be verified. So far, authorized access has been based on PINs, passwords etc. The problem is that this is not always the most convenient and secure way to $\log$ on to a system. The principal drawbacks are security issues (passwords can be, and often are, given away to colleagues, can be known by non-authorized persons etc.), convenience issues (e.g. password has to be changed, extra time to enter a password, forgetting a PIN) etc [8]. As an alternative to the use of PINs and passwords, biometric information can be used to verify the identity of an individual by his or her characteristics.

The human fingerprint is unique and can therefore successfully be used in a biometric verification system that in a near future we will be using our fingerprint to log on to our computer, internet, mail, cellular phones, making transactions etc[7]. 


\subsection{Historical Background of Fingerprint Recognition:}

One of the reasons for which fingerprint recognition is so promising is that, unlike iris scanning or other relatively untested biometrics, the U.S. and other countries have extensive real-world experience with fingerprint recognition[6]. In ancient China thumbprints were used on clay seals to prove identity in financial transactions. In 1686, Marcello Malpighi, a professor of anatomy at the University of Bologna, wrote about ridges, loops, and spirals in fingerprints. In 1823, Professor Purkinji from the University of Breslau described nine basic fingerprint patterns. These pattern descriptors are still used today. In 1823, Dr. Henry Faulds wrote an article describing fingerprints as a means of personal identification. He is credited with the first fingerprint identification in law enforcement by obtaining a conviction based on correctly identifying a greasy print left on an alcohol bottle. In 1882, Gilbert Thompson of the U.S. Geological Survey used his own fingerprint on a document to prevent forgery. In 1892, Sir Francis Galton, a British anthropologist, published the first fingerprint classification system and established the individuality and permanence of fingerprints. The "minutia points" Galton identified are still used today. In 1901, Scotland Yard adopted the GaltonHenry fingerprint identification system, an adaptation of Galton's observations by Sir Edward Henry, chief commissioner of the London metropolitan police. In 1903, The New York State prison system began the first systematic use of fingerprints in the U.S. for identifying known criminals. In 1904, The U.S. Army first began using fingerprints to identify enlisted personnel. In 1904, Juan Vucetich of the Buenos Aires police published his system of fingerprint identification, which helped him identify a murderer by studying fingerprints left on a door-post. His method is still used today. From 1905-1930, Law enforcement agencies across the U.S. turned to fingerprints for personal identification. Many began to send copies of their fingerprint cards to the National Bureau of Criminal Identification established by the International Association of Police Chiefs. In 1919, Congress established the Identification Division of the F.B.I. The National Bureau and Leavenworth consolidated their files to form the nucleus of the current F.B.I. fingerprint files.

\subsection{Biometrics}

Biometrics is the science of verifying the identity of an individual through physiological measurements or behavioral traits. Since biometric identifiers are associated permanently with the user they are more reliable than token or knowledge based authentication methods [5].

\subsubsection{Various kinds of biometrics}

Physical biometrics: These involve some form of physical measurement and includes modalities such as face, fingerprints, iris-scans, hand geometry etc.

Behavioral biometrics: These are usually temporal in nature and involves measuring the way in which a user performs certain tasks. This includes modalities such as speech, signature, gait, keystroke dynamics etc.

Chemical biometrics: This is still a nascent field and involves measuring chemical cues such as odor and the chemical composition of human perspiration.

\subsubsection{Some common biometrics}

DNA: Deoxyribo Nucleic Acid (DNA) is the one-dimensional ultimate unique code for one's individuality, except for the fact that identical twins have identical DNA patterns. [18].

Ear: It is known that the shape of the ear and the structure of the cartilaginous tissue of the pinna are distinctive. The ear recognition approaches are based on matching the distance of salient points on the pinna from a landmark location on the ear.

Face: The face is one of the most acceptable biometrics because it is one of the most common methods of recognition that humans use in their visual interactions [18]. It is very challenging to develop face recognition techniques that can tolerate the effects of aging, 
DOI: https://dx.doi.org/10.26808//rs.ca.i10v2.01 International Journal of Computer Application (2250-1797) Issue 10 Volume 2, March-April 2020

facial expressions, slight variations in the imaging environment, and variations in the pose of the face with respect to the camera (2D and 3D rotations).

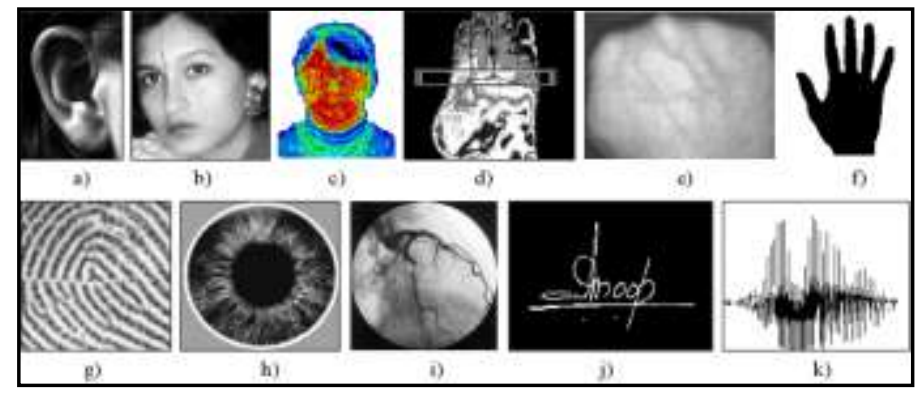

Figure 1.1 Some of the biometrics is shown

a) ear, b) face, c) facial thermo gram, d) hand thermo gram, e) hand vein, f) hand geometry, g) fingerprint, h) iris, i) retina, j) signature, and k) voice.

Hand and finger geometry: Some features related to a human hand (e.g., length of fingers) are relatively invariant and peculiar (although not very distinctive) to an individual. The image acquisition system requires cooperation of the subject and captures frontal and side view images of the palm flatly placed on a panel with outstretched fingers.

Iris: Iris image is typically captured using a non-contact imaging process. The iris recognition technology is believed to be extremely accurate and fast [18].

Signature: The way a person signs his name is known to be a characteristic of that individual. Signatures are a behavioral biometric that change over a period of time and are influenced by physical and emotional conditions of the signatories [18].

Voice: Voice is an acceptable biometric in almost all societies. Voice may be the only feasible biometric in applications requiring person recognition over a telephone. Voice is affected by a person's health, stress, emotions, and so on.

\begin{tabular}{|l|l|}
\hline \multicolumn{1}{|c|}{ Biometric Authentication } & \multicolumn{1}{c|}{$\begin{array}{c}\text { Password/Key based } \\
\text { authentication }\end{array}$} \\
\hline $\begin{array}{l}\text { Based on physiological measurements or } \\
\text { behavioral traits }\end{array}$ & $\begin{array}{l}\text { Based on something that the user } \\
\text { 'has' or 'knows' }\end{array}$ \\
\hline Authenticates the user & Authenticates the password/key \\
\hline Is permanently associated with the user & Can be lent, lost or stolen \\
\hline Biometric templates have high uncertainty & Have zero uncertainty \\
\hline Utilizes probabilistic matching & $\begin{array}{l}\text { Requires exact match for } \\
\text { authentication }\end{array}$ \\
\hline
\end{tabular}

Table: 1.1 Difference between Biometrics and Token/Password system

\subsection{Fingerprint as a biometrics}

Fingerprints were accepted formally as valid personal identifier in the early twentieth century and have since then become a de-facto authentication technique in law-enforcement agencies worldwide [3]. The FBI currently maintains more than 400 million fingerprint records on file. Fingerprints have several advantages over other biometrics, such as the following:

High universality: A large majority of the human population has legible fingerprints and can therefore be easily authenticated.

High distinctiveness: Even identical twins who share the same DNA have been shown to have different fingerprints, since the ridge structure on the finger is not encoded in the genes of an individual [3].

High permanence: The ridge patterns on the surface of the finger are formed in the womb and remain invariant until death except in the case of severe burns or deep physical injuries. 
DOI: https://dx.doi.org/10.26808//rs.ca.i10v2.01 International Journal of Computer Application (2250-1797) Issue 10 Volume 2, March-April 2020

Easy collect ability: The process of collecting fingerprints has become very easy with the advent of online sensors. These sensors are capable of capturing high resolution images of the finger surface within a matter of seconds [3].

Wide acceptability: While a minority of the user population is reluctant to give their fingerprints due to the association with criminal and forensic fingerprint databases, it is by far the most widely used modality for biometric authentication.

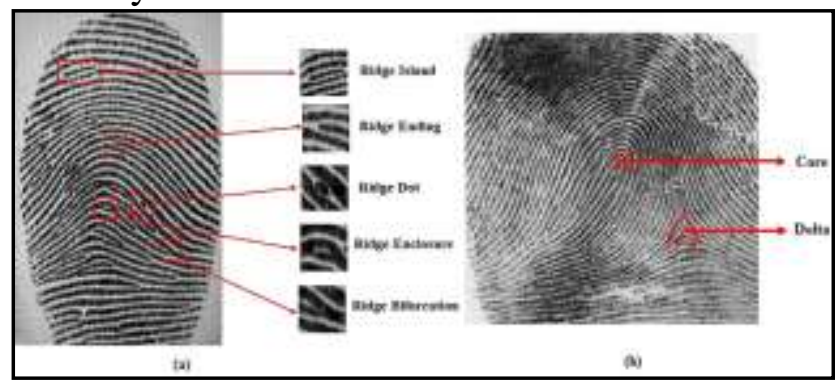

Figure 1.2: (a) Local Features: Minutiae (b) Global Features: Core and Delta

\subsection{Fingerprint Recognition Technique}

A large number of approaches have been designed over the last 40 years, and many of them have been explicitly designed to be implemented on a computer [2]. Categorization of fingerprint matching approaches is:

Correlation-based matching: Two fingerprint images are superimposed and the correlation (at the intensity level) between corresponding pixels is computed for different alignments (e.g., various displacements and rotations) [2].

Minutiae-based matching: Minutiae are extracted from the two fingerprints and stored as sets of points in the two dimensional plane. Minutiae matching essentially consist of finding the alignment between the template and the input minutiae sets that result in the maximum number of minutiae pairings [2].

Ridge feature-based matching: Minutiae extraction is difficult in very low-quality fingerprint images, whereas other features of the fingerprint ridge pattern (e.g., local orientation and frequency, ridge shape, texture information) may be extracted more reliably than minutiae [2].

\subsection{Objectives of the study}

The main objective is to implement the Fingerprint Verification System. To achieve the main objective the following sub objectives will be carried out: (i) Image acquisition (ii) Image enhancement (iii) Feature extraction (iv) Template generation (v) Verification

\section{Fingerprint Recognition Theory}

\subsection{What is Fingerprint?}

Fingerprint look at the patterns found on a fingertip. Fingerprints are composed of ridges, the elevated lines of flesh that make up the various patterns of the print, separated by valleys [figure2.1]. Ridges form many patterns, including loops, whorls, arches and more. Minutiae are discontinuities in the ridges, which can take the form of various ridge endings, bifurcations (forks), crossovers (intersections) [19].

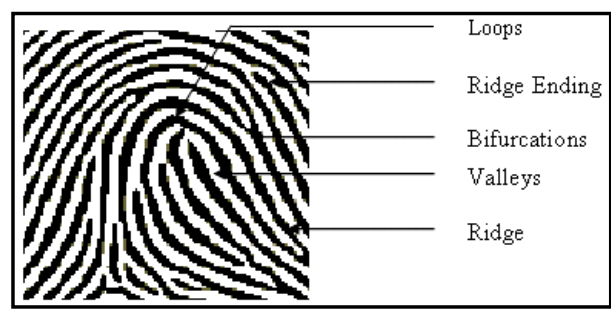

Figure 2.1: Typical Fingerprint Features 
Ridges: The skin on the inside surfaces of our hands, fingers, feet and toes are "ridged". It is the more differences in the way, friction ridges are patterned, broken, and forked which make ridged kin areas, including fingerprints unique.

\subsection{Fingerprint Recognition Modes}

The term fingerprint recognition can be either in the identification mode or in the verification mode depending on the application (Figure 2.2)

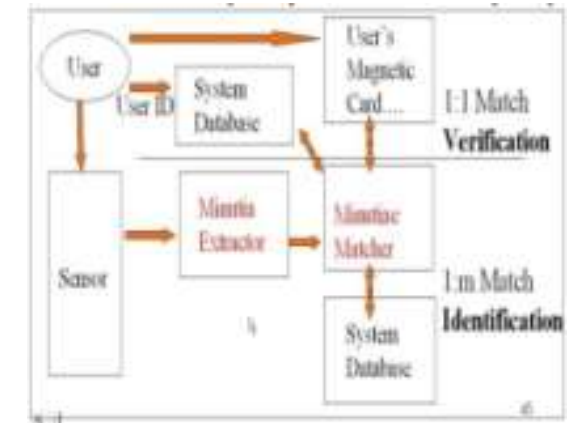

Figure 2.2: Verification vs. Identification

Fingerprint verification is to verify the authenticity of one person by his fingerprint. The user provides his fingerprint together with his identity information like his ID number. The fingerprint verification system retrieves the fingerprint template according to the ID number and matches the template with the real-time acquired fingerprint from the user. Usually it is the underlying design principle of AFVS [19].

\subsection{Advantages and applications of fingerprint}

Advantages: No need to remember passwords or pins or carry ID cards, keys or tokens. Fingerprint cannot be forgotten, lost or stolen and cannot be transferred. No recurring costs on new ID cards, no output lost due to forgotten passwords. It is safe, user-friendly, nonintrusive and accepted widely.

Applications: Used in Attendance system in offices, industries, universities, housing complexes. Used by Law enforcement agencies for criminal investigation and surveillance. Used by Government for smart cards, elections and passports, biometrics ID cards. Used for Network security, E-Business, Banks, PC security, Door locks.

\subsection{Fingerprint acquisition}

There are two primary methods of capturing a fingerprint image: (i) Inked (offline) (ii) Live scan (ink-less).

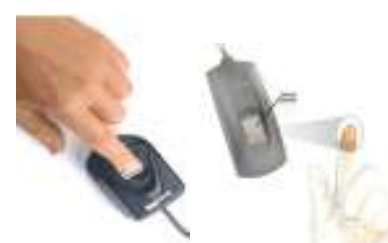

Figure 2.3: Fingerprint Acquisition technique using Live Scan by using a Biometric Fingerprint Scanner

An inked fingerprint image is typically acquired in the following way: a trained professional obtains an impression of an inked finger on a paper and the impression is then scanned using a flat bed document scanner.

The live scan fingerprint is a collective term for a fingerprint image directly obtained from the finger without the intermediate step of getting an impression on a paper. 
The fingerprint image of the same person can be looked different due to several acquisition techniques.

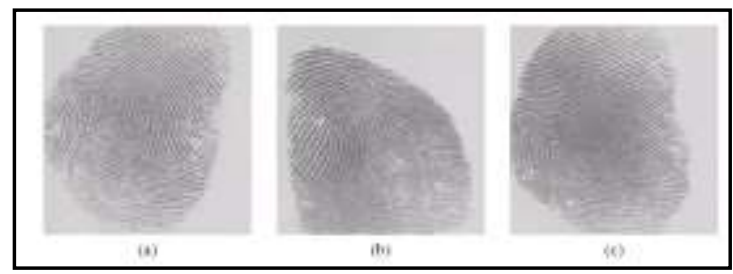

Figure 2.4: Fingerprint Images (a), (b), (c) are captured with a flat bed document scanner and all the three images are from the same individual's finger. The image quality may become poor due to scanner quality, and some other biological reasons. [Figure 2.5], [Figure 2.6]
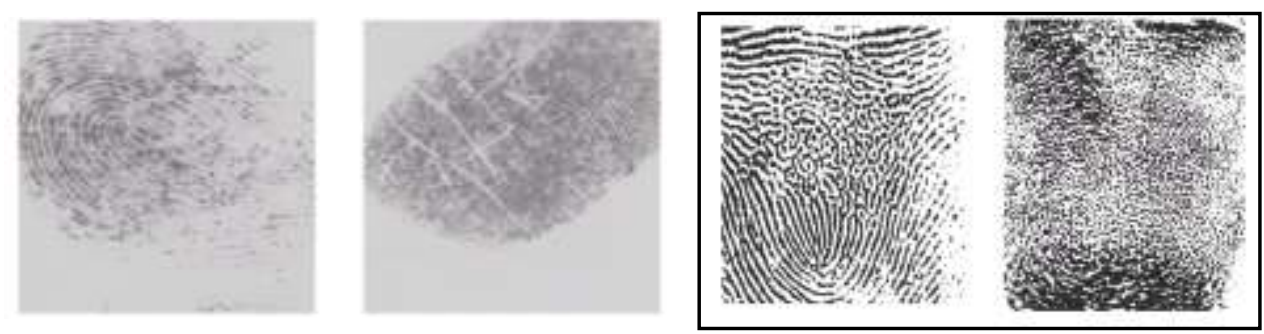

Figure 2.5 Fingerprint Images of Poor Quality Poor Quality

Figure 2.6: Fingerprint Images of The very

\subsection{Fingerprint features}

To classify a fingerprint it should be identified first, A Fingerprint can be identified by the following features: (i) Global features (ii) Local features

\section{Global features:}

Global features are those characteristics that anyone can see with naked eye. Global features include: Basic ridge patterns, Pattern area, Core area, Delta, Type lines, Ridge count

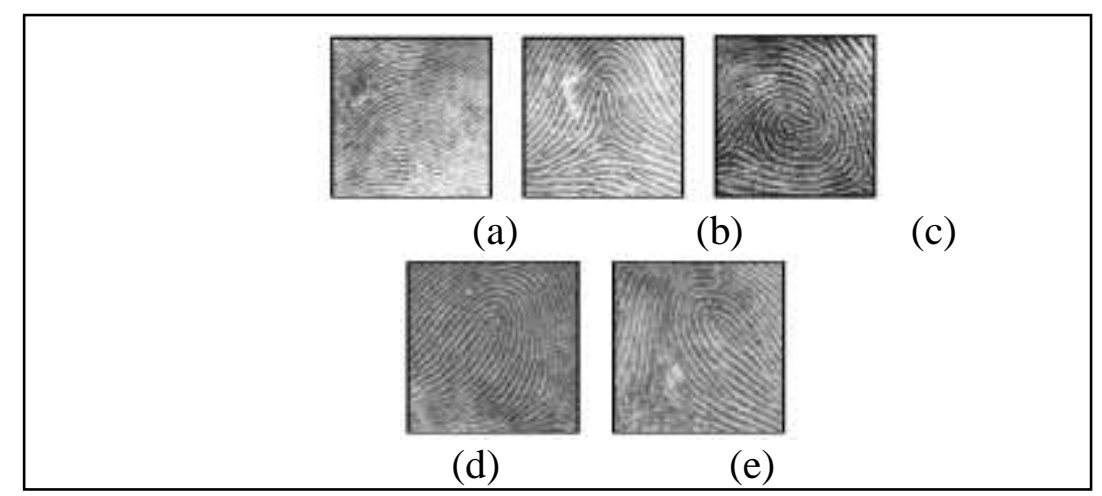

Figure 2.8: Fingerprint classification (a) arch (b) delta (c) whorl (d) left loop (e) right loop

Loop: The loop is the most common type of fingerprint pattern and accounts for about $65 \%$ of all prints.[1], There are two types of Loop: (i) Left Loop (ii) Right loop

Arch: The Arch pattern is a more open curve than the Loop. There are two types of arch patterns - the Plain Arch and the Tented Arch.[1]

Whorl: Whorl patterns occur in about $30 \%$ of all fingerprints and are defined by at least one ridge that makes a complete circle.[1] 
Pattern Area: The Pattern Area is the part of the fingerprint that contains all the global features. Fingerprints can be read and classified based on the information in the Pattern Area. Certain minutia points that are used for final identification might be outside the Pattern Area.

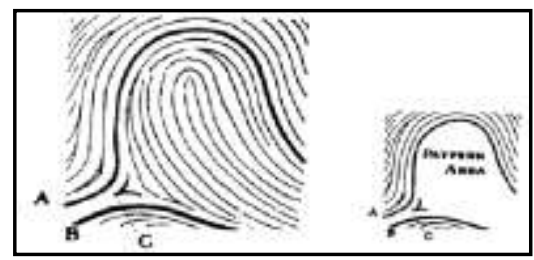

Figure 2.9: Fingerprint classification, Pattern area of the Fingerprint image

Core Point: The Core Point, located at the approximate center of the finger impression.

Delta: The Delta is the point on the first bifurcation, abrupt ending ridge, meeting of two ridges, dot and fragmentary ridge.

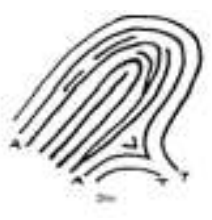

Figure 2.10

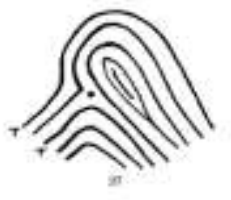

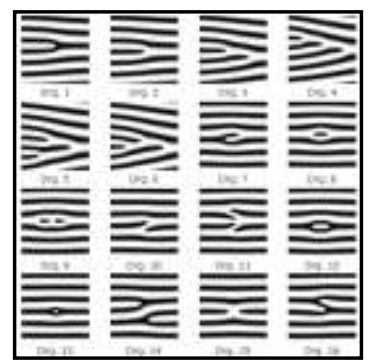

Figure 2.11

Figure 2.10: Fingerprint Classifications: Delta.

Figure 2.11: Fingerprint Classifications: 16 different categories of the fingerprint ridge patterns of type line

\section{Type lines:}

Type Lines are the two innermost ridges that start parallel, diverge, and surround or tend to surround the pattern area.

\section{Local features:}

It is commonly known as minutia points. They are tiny, unique characteristics of fingerprint ridges that are used for positive identification.

Now, to create such a model one should understand first the essence of the phenomenon, and also to develop methods of its reliable and easy algorithmisation. As a starting point in our attempts of creation of such a model we selected the problem of synthesis of pattern of dermatoglyphics - chiefly minutiae.

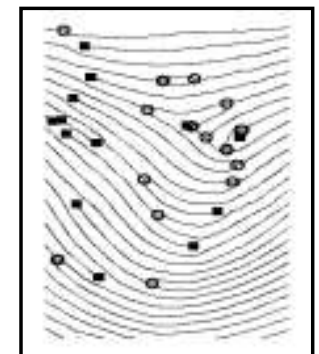

Figure 2.12: Local Features of a Fingerprint

\subsection{Image Enhancement}

Image enhancement is to fill "holes" and to increase the contrast. This process making continuous of the non-continuous ridges and valleys of the fingerprint and extract the highly interesting foreground from the noisy and irrelevant background and preserve valid minutiae. 
DOI: https://dx.doi.org/10.26808//rs.ca.i10v2.01 International Journal of Computer Application (2250-1797)

Issue 10 Volume 2, March-April 2020

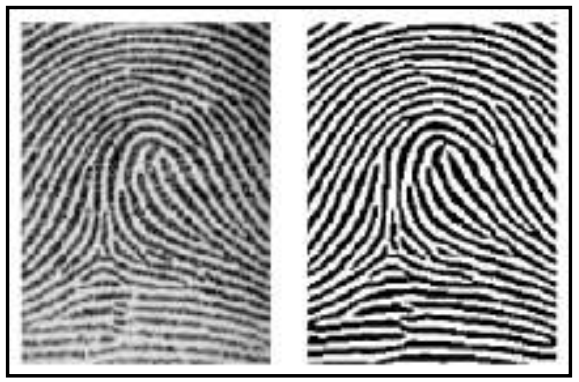

Figure2.13: (a) Input image $\quad$ (b) Enhanced image

\section{Recognition Methodology:}

\subsection{Block diagram of fingerprint verification technique:}

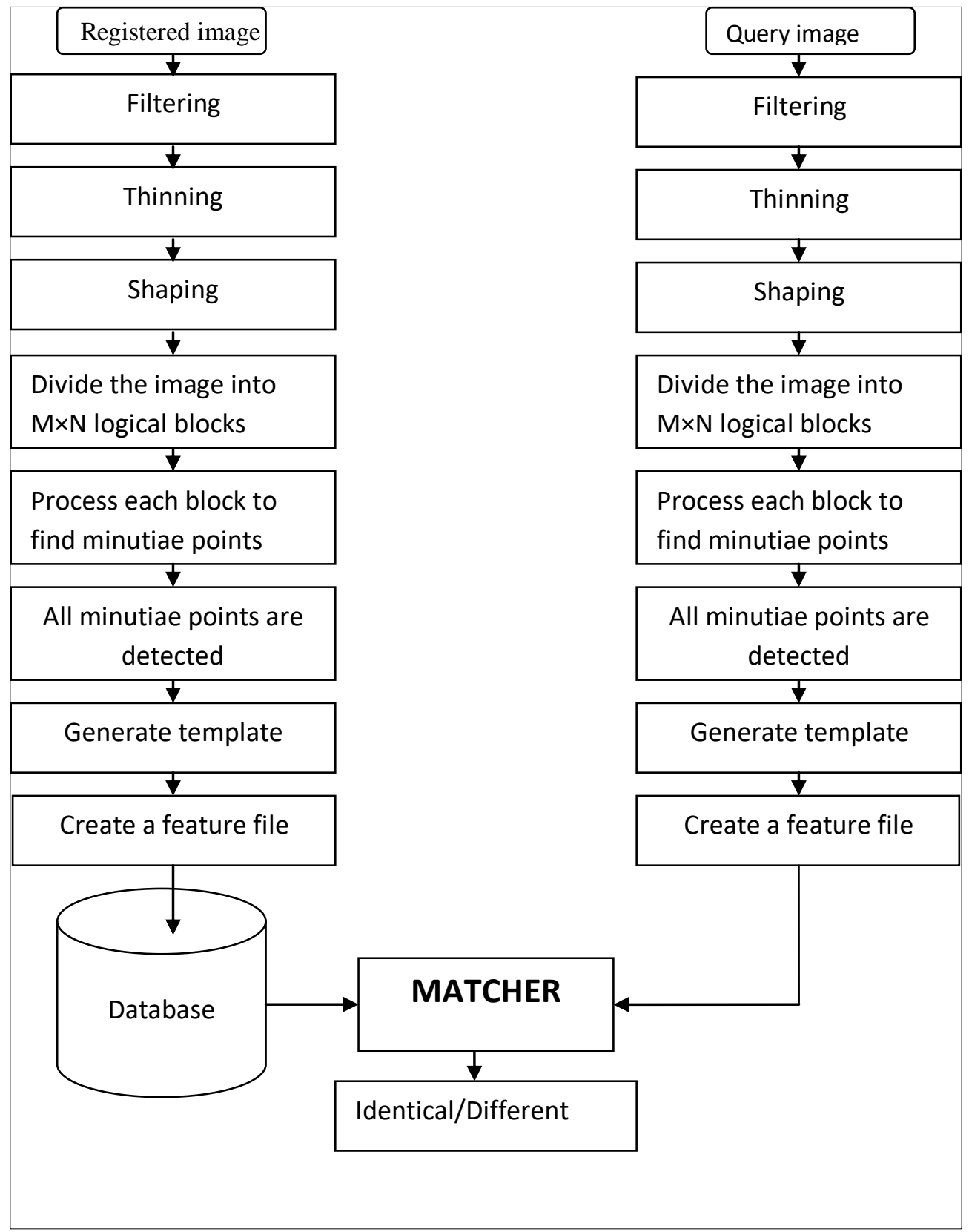

"Fingerprint Verification System (FVS)" program is used to perform the above steps which are the implementation of the following algorithms: 


\subsection{Image processing}

\subsubsection{Image filtering/Binarization}

In application, an image of 24 bits of a fingerprint is used. The given image is a collection of pixels, where each pixel contains three colors in different ratio. Here each pixel is a return value of RGB function, which has three parameters, such as RED, GREEN and BLUE having values in the range 0 to 255 . For example, return value of RGB $(0,0,0)$ contains BLACK and return value of $\operatorname{RGB}(255,255,255)$ contains WHITE. To filter the input image, we have to read RGB value of each pixel. Then we build the condition as follows, If a pixel contains RGB (THRESHOLD, THRESHOLD, THRESHOLD) or any of that three parameters is less than THRESHOLD (The THRESHOLD is a value between 0 to 255), then we make a decision to filter the image and replace that pixel by the RGB $(0,0,0)$. If a pixel contains RGB (THRESHOLD+1, THRESHOLD+1, THRESHOLD+1) or any of that three parameters is greater than (THRASHOLD+1) then replace that pixel by the $\operatorname{RGB}(255,255,255)$.

\section{Algorithm for Image Filtering/Binarization:}

1. Take input image of WIDTH $\times$ HEIGHT. Read each pixel's RGB values, which contain three numerical values, taking range of 0 to 255 .

2. If all of three return values of RGB function are smaller than 128, then Put a pixel of BLACK color $[\mathrm{RGB}(0,0,0)]$ to the corresponding coordinates. Else

Put a pixel of WHITE color [RGB $(255,255,255)]$ to the corresponding coordinates.

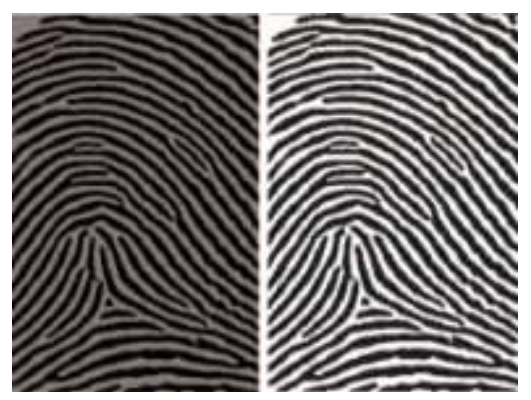

(a) (b)

Figure 3.2: Image processing (a) Input image, (b) filtered/binarized image

\subsubsection{Image enhancement}

After filtering the image, we gained an image of only two colors, BLACK and WHITE. Here the black pixels/colors mean the ridge lines of fingerprints, which haven't the same thickness all over the image. To overcome this limitation, the help of 'enhancing' is taken. In the enhancing phase we have performed two steps: (a) Image thinning (b) Image filling/shaping

\subsubsection{Image Thinning}

By enhancing the limitations of variant thickness problem can be overcome, but an unsmooth image is obtained. The 'lining' is the initial step to overcome that limitation.

\section{Algorithm for Image Thinning: First Pass:}

1. Read a pixel of coordinates $(\mathrm{J}, \mathrm{I})$, Where $0<=\mathrm{J}<$ WIDTH, And $0<=$ I $<$ HEIGHT.

2. If the pixel is WHITE, i,e, RGB function returns three values, which all are greater than THRESHOLD,

Do nothing; 
Else

For (I+1) to HEIGHT do

$\mathrm{A}:=$ number of BLACK pixels until it is WHITE;

For I to 0 do

$\mathrm{B}:=$ number of BLACK pixels until it is WHITE;

3. If $A=B$ then

Put a RED pixel at coordinates (J, I); Else

Do nothing

\section{Second Pass:}

1. Read a pixel of coordinates (J,I),

Where $0<=\mathrm{J}<$ WIDTH,

And $0<=$ I $<$ HEIGHT.

3. If the pixel is RED

Put a BLACK pixel at coordinates (J, I);

4. Else

Put a WHITE pixel at coordinates (J, I);

\section{Third Pass:}

1. Read a pixel of coordinates (J,I),

Where $0<=\mathrm{J}<$ WIDTH,

And $0<=$ I $<$ HEIGHT.

2. If the pixel is BLACK and it's all eight neighbors are white

Put a WHITE pixel at coordinates (J, I);

Else

Do nothing

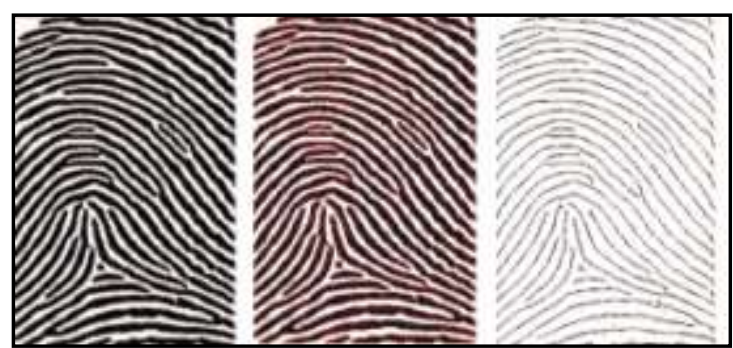

(a)

(b)

(c)

Fig 3.3 Image processing (a) Filtered image (b) Intermediate step of thinning (c) Thinned image

\subsubsection{Image shaping/Fill lining}

The 'Fill lining' is the goal step to smooth the lined image to overcome the limitations of enhanced image. In this step, Lined image is used as input image and scanned it either raw by raw or column by column. Whenever a single BLACK pixel is found out, a filled circle is drawn corresponding to that pixel to smooth the image.

\section{Algorithm For Image Shaping/filling:}

1. Read a pixel of coordinates $(\mathrm{J}, \mathrm{I})$.

Where $0<=\mathrm{J}<=$ WIDTH,

And $0<=$ I $<=$ HEIGHT.

2. If the pixel is WHITE, then Do nothing .

Else Draw s filled circle of BLACK color. 


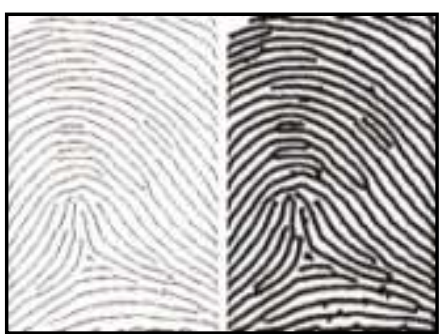

(a) Issue 10 Volume 2, March-April 2020

Figure 3.4: Image processing (a) lined image (b) Filled lining

\subsubsection{Finding Minutiae Points}

Minutiae points are tiny, unique characteristics of fingerprint ridges that are used for positive identification. To create such a model one should understand first the essence of the phenomenon, and also to develop methods of its reliable and easy algorithmisation. As a starting point in our attempts of creation of such a model the problem of synthesis of pattern of dermatoglyphics is selected - chiefly minutiae This model allows digital coding of fingerprints from some two-dimensional function of very interesting qualities. [Figure 3.5]

\section{Algorithm 3.5: Finding Minutiae point}

1. Divide the image of WIDTH $\times$ HEIGHT pixels into $\mathrm{M} \times \mathrm{N}$ logical blocks, where each block contains $\mathrm{U} \times \mathrm{V}$ pixels and $\mathrm{M}=\mathrm{WIDTH} / \mathrm{U}$ and $\mathrm{N}=\mathrm{HEIGHT} / \mathrm{V}$.

2. Now read each block from left to right direction.

A) Starting pixel of each block is denoted by $(\mathrm{J}, \mathrm{I})$, where,

$\mathrm{J}:=$ Current max of $\mathrm{X}$-axis - Block range of $\mathrm{X}$-axis;

$\mathrm{I}:=$ Current max of $\mathrm{Y}$-axis $-\mathrm{Block}$ range of $\mathrm{Y}$-axis;

B) Read a pixel of coordinates $(\mathrm{X}, \mathrm{Y})$, where,

$\mathrm{X}:=\mathrm{X}$ to $(\mathrm{X}+$ Block range of $\mathrm{X}$-axis);

C) If the pixel is WHITE,

do nothing. is WHITE.;

Else for (Y-Block range of $\mathrm{Y}$-axis) to $\mathrm{Y}$ do $\mathrm{A}:=$ number of BLACK pixels until it is WHITE.;

for $(\mathrm{Y}+1)$ to $(\mathrm{Y}+$ Block range of $\mathrm{Y}$-axis) do $\mathrm{B}:=$ number of BLACK pixels until it

D) $\mathrm{TEMP}:=(\mathrm{A}+\mathrm{B}) / 2$;

If $\mathrm{A}>\mathrm{B}$ then $\mathrm{Y}:=\mathrm{Y}-(\mathrm{TEMP}-\mathrm{B})$

Else $\mathrm{Y}:=\mathrm{Y}+(\mathrm{TEMP}-\mathrm{A})$;

E) Indicate the new point $(\mathrm{X}, \mathrm{Y})$, such as, it will be not read next times.

F) $\mathrm{J}:=\mathrm{J}+1$;

If ( $\mathrm{J}<$ any coordinates on $\mathrm{X}$-axis of the block) then $\mathrm{A}:=0 ; \mathrm{B}:=0$; go to $2(\mathrm{~B})$

Else If $(\mathrm{J}, \mathrm{Y})$ is contained the block then select the point $(\mathrm{J}, \mathrm{Y})$ as a minutiae point;

G) I := I+1;

If ( $\mathrm{I}<$ any coordinates on $\mathrm{Y}$-axis of the block) then $\mathrm{J}:=$ Current max of $\mathrm{X}$-axis -

Block range of $\mathrm{X}$-axis;

go to $2(\mathrm{~B})$

Else Analyze next new block;

Similarly, it is important to analyze the each block from

(i) Right to left direction. (ii) Up to down direction and (iii) Down to up direction. 


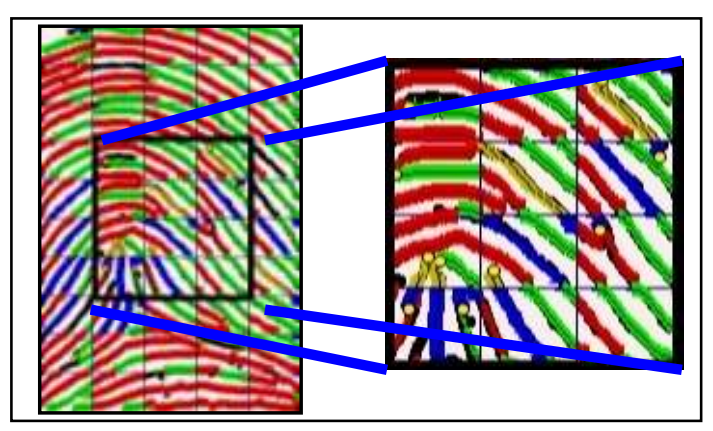

Figure 3.5: Minutiae point detection

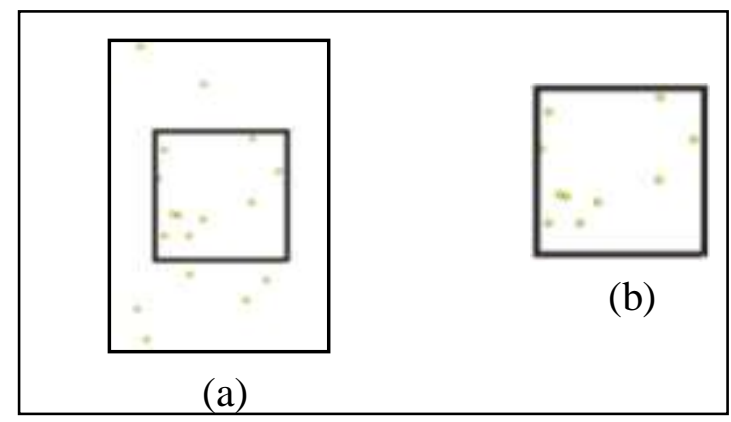

Figure 3.6

\subsubsection{Template generation}

After finding the minutiae points of the input image, the background image is removed and keep only the minutiae points to generate a template, the step is to clip a predetermined position to generate a template which bear some sophisticated data to generate a corresponding data file (*.fpf), which file contains the

- Total number of minutiae points in the image - Total number of template minutiae points Interrelated distance of each template points termed as correlation

Figure3.6: (a) Minutiae points are shown to generate Template of the Input Image,

(b) Clipped Template of the Input Image

\begin{tabular}{|c|c|c|}
\hline Minutiae Count & $\mathrm{X}$ & $\mathrm{Y}$ \\
\hline 1 & 63 & 134 \\
\hline 2 & 56 & 169 \\
\hline 3 & 79 & 214 \\
\hline 4 & 63 & 239 \\
\hline 5 & 91 & 239 \\
\hline 6 & 193 & 160 \\
\hline 7 & 162 & 198 \\
\hline 8 & 73 & 212 \\
\hline 9 & 73 & 212 \\
\hline 10 & 107 & 219 \\
\hline 11 & 163 & 120 \\
\hline
\end{tabular}

\begin{tabular}{|c|c|}
\hline Minutiae Count & Distance \\
\hline 1 & 36 \\
\hline 2 & 51 \\
\hline 3 & 30 \\
\hline 4 & 28 \\
\hline 5 & 129 \\
\hline 6 & 49 \\
\hline 7 & 90 \\
\hline 8 & 0 \\
\hline 9 & 35 \\
\hline 10 & 114 \\
\hline
\end{tabular}

TABLE 3.1

TABLE 3.2: Total no of template minutiae points are 11

TABLE 3.1 Co-ordinates of the template minutiae

TABLE 3.2: Correlated Distance of the template minutiae points from each other points

\subsubsection{Fingerprint Verification}

Verification is the final stage of the study. To verify a person he/she must be registered first. So the steps are:

- Registration • Verification

Registration: To authenticate a person, it is needed to registry one by registration process. This process takes the person's fingerprint as an image format and processed that image as few steps such as filtering, enhancing (including thining and shaping). Then it requires minutiae points finding technique and selects minutiae points as features, then generates a template and stores it for further uses, such as fingerprint verification.

Verification: To verify a person, the process takes the person's fingerprint as an image and processed that image as few steps such as filtering, enhancing. Then it requires minutiae points finding technique and selects features, and then load the templates and compare with 
DOI: https://dx.doi.org/10.26808//rs.ca.i10v2.01 International Journal of Computer Application (2250-1797) Issue 10 Volume 2, March-April 2020

the information gathered from verifying person. If it obtains any template matched with that of verifying person, it makes a decision that the person was authenticated.

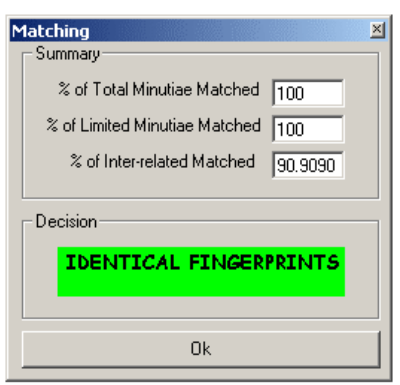

(a)

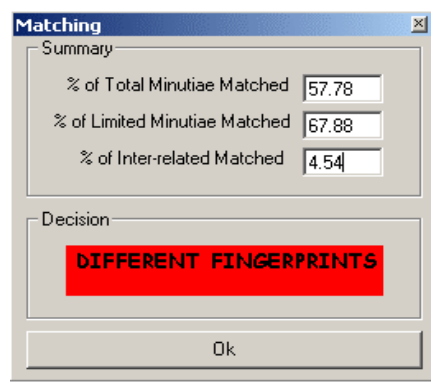

(b)

figure 3.7: Fingerprint Verification, (a) Show message "Identical Fingerprints" if the two fingerprints are similar detected by the FVS, (b) Show message "Different Fingerprints" if the two fingerprints are dissimilar detected by the FVS

\section{Algorithm 3.5: Matching}

1. For $\mathrm{i}=1$ to Total Template Minutiae Points-1 do

Find Euclidean Distance between two points $(\mathrm{i}, \mathrm{i}+1)$ as follows

$\operatorname{Dis}(\mathrm{i}, \mathrm{i}+1)=\left(\left(\mathrm{i} \_\mathrm{x}-(\mathrm{i}+1) \_\mathrm{x}\right)^{2}+\left(\mathrm{i} \_\mathrm{y}-(\mathrm{i}+1) \_\mathrm{y}\right)^{2}\right)^{1 / 2}$

2. Repeat step 1 for the verified image also.

3. Calculate total number of correlated distances of-both images.

4. Find similarity between Total Minutiae points of both images

5. Find similarity between Template Minutiae points of both images

6 If similarity score $>$ Threshold

Authentication successful

Else Authentication failure

\section{EXPERIMENTAL RESULTS}

\begin{tabular}{|c|c|c|c|c|c|c|}
\hline \multicolumn{2}{|c|}{ Person } & $\begin{array}{c}\text { Total Minutiae } \\
\text { contained in } \\
\text { taken image }\end{array}$ & $\begin{array}{c}\text { Minutiae } \\
\text { selected by } \\
\text { FVS }\end{array}$ & $\begin{array}{c}\text { Dropped } \\
\text { minutiae } \\
\text { by FVS }\end{array}$ & $\begin{array}{c}\text { False } \\
\text { minutiae } \\
\text { by FVS }\end{array}$ & $\begin{array}{c}\text { Correct } \\
\text { Minutiae } \\
\text { by FVS }\end{array}$ \\
\hline $\begin{array}{c}\text { Person } \\
1\end{array}$ & Input 1 & 18 & 17 & 3 & 2 & 15 \\
\cline { 2 - 7 } & Input 2 & 21 & 15 & 9 & 3 & 12 \\
\hline $\begin{array}{c}\text { Person } \\
2\end{array}$ & Input 1 & 25 & 18 & 8 & 1 & 17 \\
\cline { 2 - 7 } & Input 2 & 26 & 19 & 9 & 2 & 17 \\
\hline $\begin{array}{c}\text { Person } \\
3\end{array}$ & Input 1 & 22 & 19 & 5 & 2 & 17 \\
\cline { 2 - 7 } & Input 2 & 20 & 17 & 6 & 3 & 14 \\
\hline $\begin{array}{c}\text { Person } \\
4\end{array}$ & Input 1 & 40 & 47 & 1 & 8 & 39 \\
\cline { 2 - 7 } & Input 2 & 47 & 53 & 3 & 9 & 44 \\
\hline
\end{tabular}

TABLE 4.1: Classifications of Minutiae point of an image.

In Table 4.1, it contains some particular images with Actual minutiae points contained in the image, Minutiae selected by the proposed technique FVS, Dropped minutiae points by FVS, False minutiae points by FVS, and Correct minutiae points acquired by FVS.

Total minutiae points contained in taken image are calculated manually to find out the accuracy of proposed minutiae finding technique named FVS. Dropped minutiae points are that which is contained in taken image but not in the image processed by the FVS, i.e., failed to recognize that points as minutiae points. False minutiae points are that which are not 
DOI: https://dx.doi.org/10.26808//rs.ca.i10v2.01 International Journal of Computer Application (2250-1797) Issue 10 Volume 2, March-April 2020

contained in taken image as minutiae points but the FVS select that as minutiae points. Then correct number of minutiae points are selected by FVS is calculated by the difference of dropped and false minutiae points from total minutiae points contained in taken image calculated manually.

\begin{tabular}{|c|c|c|c|c|c|}
\hline \multicolumn{2}{|c|}{ Image } & \multirow{2}{*}{$\begin{array}{c}\text { Total Minutiae } \\
\text { contained in } \\
\text { taken image }\end{array}$} & \multirow{2}{*}{$\begin{array}{c}\text { Percentage of false } \\
\text { minutiae contained } \\
\text { in FVS image }\end{array}$} & \multirow{2}{*}{$\begin{array}{c}\begin{array}{c}\text { Percentage of } \\
\text { dropped minutiae } \\
\text { contained in FVS } \\
\text { image }\end{array} \\
16.67 \%\end{array}$} & \multirow{2}{*}{$\begin{array}{c}\begin{array}{c}\text { Percentage of } \\
\text { Correct minutiae } \\
\text { contained in FVS } \\
\text { image }\end{array} \\
83.33 \%\end{array}$} \\
\hline Perso & $\begin{array}{c}\text { Inpu } \\
\text { t } 1\end{array}$ & & & & \\
\hline n 1 & $\begin{array}{c}\text { Inpu } \\
\text { t } 2\end{array}$ & 21 & $14.28 \%$ & $42.85 \%$ & $57.16 \%$ \\
\hline \multirow{2}{*}{$\begin{array}{c}\text { Perso } \\
\text { n } 2\end{array}$} & $\begin{array}{c}\text { Inpu } \\
\text { t } 1\end{array}$ & 25 & $4 \%$ & $32 \%$ & $68 \%$ \\
\hline & $\begin{array}{c}\text { Inpu } \\
\text { t } 2\end{array}$ & 26 & $7.69 \%$ & $34.61 \%$ & $65.39 \%$ \\
\hline \multirow{2}{*}{$\begin{array}{c}\text { Perso } \\
\text { n } 3\end{array}$} & $\begin{array}{c}\text { Inpu } \\
\text { t } 1\end{array}$ & 22 & $9.09 \%$ & $22.73 \%$ & $77.27 \%$ \\
\hline & $\begin{array}{c}\text { Inpu } \\
\text { t } 2\end{array}$ & $20 \%$ & $15 \%$ & $30 \%$ & $70 \%$ \\
\hline \multirow{2}{*}{$\begin{array}{c}\text { Perso } \\
\text { n } 4\end{array}$} & $\begin{array}{c}\text { Inpu } \\
\text { t } 1\end{array}$ & $40 \%$ & $20 \%$ & $2.5 \%$ & $97.5 \%$ \\
\hline & $\begin{array}{c}\text { Inpu } \\
\text { t } 2\end{array}$ & $47 \%$ & $19.15 \%$ & $6.38 \%$ & $93.62 \%$ \\
\hline
\end{tabular}

TABLE 4.2: Percentage of different types of minutiae points

In Table 4.2, it contains the total number of minutiae points contained in taken image, percentage of false minutiae points by FVS, percentage of dropped minutiae points by FVS and percentage of correct minutiae points by FVS.

\section{CONCLUSIONS}

Fingerprint is the flexible and highly secured paradigm, which is shifting the Biological Security to the Electronic Security. Here we have taken images from various websites and other reliable sources rather than using a sophisticated Biometric Fingerprint Scanner. Due to some technical problem. It cannot detect the $100 \%$ minutiae points, due to some technical problem such as poor quality image or noisy image. In future, we would like to use a sophisticated Biometric Fingerprint Scanner to take fingerprint from the donor. We also would like to improve the image processing Algorithms so that it can detect the maximum number of minutiae points in case of a poor quality image.

\section{REFERENCES}

1. Martin Sagayam, D. Narain Ponraj, J. Jenkin Winston, "Authentication of biometric system using fingerprint recognition with Euclidean distance and neural network classifier", Project: Hand posture and gesture recognition techniques for virtual reality applications: a survey, January 2019

2. Kumar, D. Ashok, and T. Ummal Sariba Begum. "A Comparative Study on Fingerprint Matching Algorithms for EVM." Journal of Computer Sciences and Applications 1.4 (2013): 55-60.

3. Wencheng Yang, Song Wang, Jiankun Hu, Guanglou Zheng and Craig Valli " Security and Accuracy of Fingerprint-Based Biometrics: A Review", Symmetry 2019, 11, 141; doi:10.3390/sym11020141 
4. Faridah Yahya ,Haidawati Nasir, Kushsairy Kadir. "Fingerprint Biometric Systems", September 2016 Trends in Bioinformatics 9(2):52-58, DOI: 10.3923/tb.2016.52.58

5. Priyanka Datta, Shanu Bhardwaj "Survey of Security and Privacy Issues on Biometric System" Publisher: Springer, In book: Handbook of Computer Networks and Cyber Security. Principles and Paradigms , January 2020, DOI: 10.1007/978-3-030-22277-2_30

6. Cole S.A. (2004) History of Fingerprint Pattern Recognition. In: Ratha N., Bolle R. (eds) Automatic Fingerprint Recognition Systems. Springer, New York, NY

7. Wencheng Yang, Song Wang, Jiankun Hu, Craig Valli. Security and Accuracy of Fingerprint-Based Biometrics: A Review, January 2019, Symmetry 11(2):141, DOI: 10.3390/sym11020141

8. Viktor Taneski, Marjan Heričko, Boštjan Brumen. Systematic Overview of Password Security Problems. Acta Polytechnica Hungarica Vol. 16, No. 3, 2019

9. BioEnable - Biometrics, Fingerprint Recognition Terminal for Time Attendance, Access control, Banking, Enterprise security, Civil IDs and more_files, http://www.bioenabletech.com/index.htm visited at 10/10/2002

10. David F. Betsch, Ph.D., Biotechnology Training Programs, Inc. "DNA Fingerprinting in Human Health and Society", http://web.mit.edu/esgbio/www/mg/geneticcounseling.html , 2002

11. John A. Richards, Xiuping Jia. "Remote Sensing Digital Image Analysis : An Introduction" http://library.caltech.edu/about/theses.htm , 2002

12. Digital Persona: Guide to Fingerprint Identification, http://www.talktoyourcomputer.com/ 2001

13. L.C. Ern, G. Sulong. Fingerprint Classification Approches: An Overview, IEEE, 0-78036703-0/01, pp. 347-350, 2001

14. R.C. Gonzales, R.E. Woods. Digital Image Processing Addison-Wesley Publishing Company, Inc. 1992

15. A.D. Brink. Grey-level Thresholding of Images Using a Correlation Criterion, Pattern Recognition Letters, No. 9, pp. 335-341, 1989

16. C. E. Chapel., Fingerprinting - A manual of Identification, Coward McCann, New York 1971.

17. https://www.biometricsinstitute.org/what-is-biometrics/types-of-biometrics/

18. G. Aguilar, G. Sanchez, K. Toscano, M. Salinas, M. Nakano and H. Perez, "Fingerprint Recognition," Second International Conference on Internet Monitoring and Protection (ICIMP 2007), San Jose, CA, 2007, pp. 32-32. 